\title{
COMMON NIGHTHAWKS IN SASKATOON
}

JIM WEDGWOOD, 610 Leslie Avenue, Saskatoon, Saskatchewan. S7H $2 Z 2$

In 1971, nighthawks seemed to be everywhere around Saskatoon. At dusk on most summer evenings our neighbourhood male was overhead, giving his distinctive peent call and making his booming dives. That year my wife, Shirley, and I counted Common Nighthawks and estimated that there were 48 males in Saskatoon. By 1981 the birds had become uncommon and a partial repeat of the earlier count yielded only seven males. In 1989, I never heard a nighthawk and received only two reports of them in the city.

As a result, in 1990, another survey was made, this time with assistance. The goals were: a better estimate of the population, a preliminary assessment of possible local causes of the decline and some idea of the status of nighthawks in Saskatchewan cities.

Procedure To find nighthawks, advantage was taken of two of their characteristics: in cities, they commonly nest on flat gravelled roofs and the males give their distinctive peent calls, generally at dusk while flying about their home ranges. The count method adopted was mainly the same as used in 1971 and described in my article on that earlier survey, which in turn had been patterned on a study in Detroit. ${ }^{9,2}$

The study area excluded the air- port and undeveloped lands, but included Field A (see map in my previous article). ${ }^{9}$ The study area was $107.3 \mathrm{sq} \mathrm{km}$ of the $139.7 \mathrm{sq} \mathrm{km}$ within the city limits and was divided into 20 sectors, Field $A$ being one of them. Field $A$, an odd-shaped, largely unbroken, stony 158-ha parcel of fescue prairie, was natural nighthawk habitat (its south end is the Silverspring prairie the Saskatoon Natural History Society and others seek to preserve).

Where possible, sector boundaries were located along major dividers such as the river, railways and freeways. Arterial streets with concentrations of flat-roofed buildings also served as sector boundaries, increasing coverage of places where birds were likely to be. Flat-roofed buildings occurred in concentrations (downtown), as integrated structures (malls), in groups (at some primary intersections), as the dominant building type in some open areas (older industrial tracts, campuses), and as isolated structures in residential areas (schools, apartments). Gravelled roofs could be found on practically any class of building, but were least common on residential and industrial structures.

The observer assigned to a sector made at least two counts, spaced at least five days apart between 15 June and 25 July. Counts began 30 


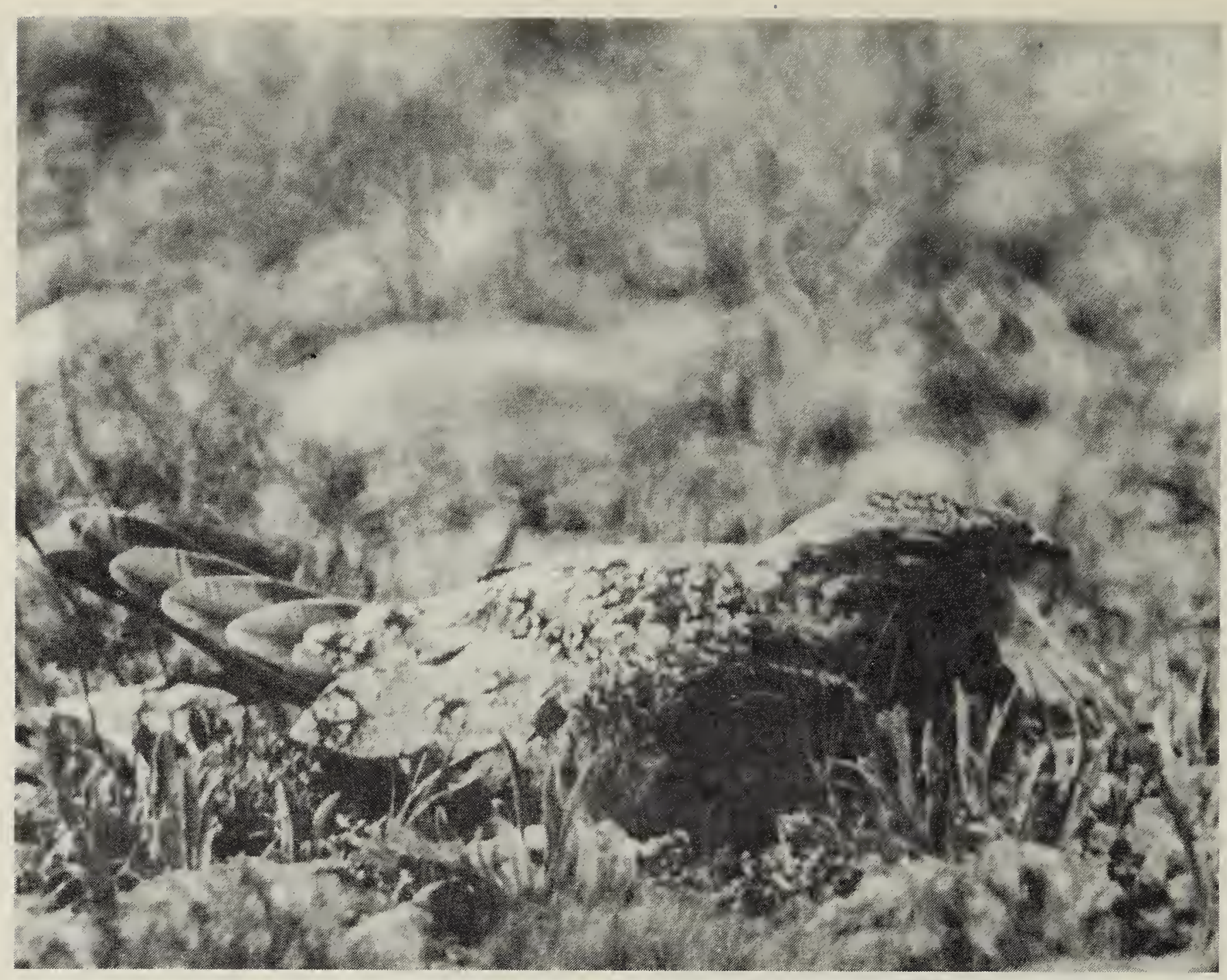

Frank A. Switzer

minutes before sunset and continued for an hour afterwards. The observer chose a route to come within two or three blocks of flat roofs, starting and finishing where they were most numerous, again to increase coverage. He or she stopped every two to four blocks in likely places for three minutes, listening for peent calls and scanning the sky. Upon detecting a male, an attempt was made to trace its path on a map and thus delineate its home range, at the same time listening for any neighbouring birds.

The procedure in 1990 differed in three major ways from 1971's. First, more observers allowed for better coverage. Second, as in 1971, the start was delayed until practically all home ranges could be established, but counts were terminated sooner, on 25 July, because we had found that home ranges were breaking up by the end of July. Third, observers individually selected the evenings for counting, as the system used in 1971 no longer worked. Then, our neighbourhood male peent-ing at length was our signal of a prospective good evening for nighthawk hunting. By 1990, however, there were too few birds in districts where most observers resided for this system to work.

The population estimate was made using records of isolated males, the traces of the birds' flight paths which sufficiently outlined home ranges, or when two males were observed at the same time. In the other instances, for example, at the boundary between two districts where more than one male might be present, an estimating technique had to be applied. $^{9}$

Count Results Twenty observers spent an average of 2.8 evenings each, making a total of 56 counts and garnering 35 observations of 
peents, booming-dive displays and sightings. An observer usually reported any nighthawks encountered even when not actually on a count. Other persons also reported sightings. As in 1971, both these kinds of incidental records, totalling 33 observations, were included with count observations, yielding 68 records in all. Analysis of them indicated a conservative estimate of 28 males present in Saskatoon during 1990.

Most - 31 - observations occurred between sunset and an hour and a quarter afterwards, peak incidence following sunset by 30 to 45 minutes (10:00-10:15 p.m. local time). Observations were most frequent from 23 to 27 June with 20 reported and 7 and 8 July with six (1.50 and 0.70 males per count). Three incidental reports of flying birds were made between 2:45 and 4:00 a.m.

An aside: two nests were reported, one on a hospital roof, the other on a pile of brick rubble in an industrial yard (Alvena Schnell, pers. comm.; fide Lloyd Saul). The female's loud hissing when a watchdog passed by drew attention to the latter.

\section{ANALYSIS}

Population The estimated decline in male numbers since 1971 was 42 percent. Because the study area had grown by 57 percent in the interval, change in density is a more meaningful measure. The estimate in 1971 was one male per $1.4 \mathrm{sq} \mathrm{km}$ of study area, in 1990 one per $3.8 \mathrm{sq} \mathrm{km}$, a third as much. Field $A$ in the city's northeastern outskirts was thought to serve as a benchmark. Its nighthawk history: five males in 1971, four in 1981 and a mere one or possibly two in 1990. Being more rural than urban, this trend may be indicative of the situation in the surrounding region, wherever suitable habitat remains.

This was not an extraordinary drop. Normal fluctuations are often greater, especially regionally. ${ }^{7}$ Indications are, however, that the decline in nighthawk numbers had been long term and general in the mid-continent, and the species was on American Birds Blue List by 1976. ${ }^{\dagger}$ Our partial survey in 1981 detected only seven males, indicating most of the decline probably had taken place by then. Though we did not cover the entire city, that survey did include 1971's hot spots and entailed 127 stops in $135 \mathrm{~km}$ of driving on eight evenings between 3 and 14 July. The initial comment from most persons asked to help with the 1990 study was that nighthawks had been scarce for years.

The trouble with the present method is that we have only snapshots, because, though providing insights, the surveys are only views of two years in isolation. Better that each had been done for three years in a row.

Another problem is that it is not known where 1971 and 1990 fit in the species' normal population cycle of peaks and valleys, given that nighthawks have one. Steven Marsden studied the incidence of clinic admissions between 1979 and 1987 of certain traumatized wildlife. ${ }^{8}$ $\mathrm{He}$ found the data were suggestive of a three-year cycle for the Common Nighthawk, there having been influxes of injured birds in 1979, 1982 and 1985 . To have been able to relate our results to a known cycle would have been useful. Unfortunately, data for the prior and following years are not available.

Though trends in other cities have 
Residential/commercial/institutional

Downtown commercial

Industrial

Field A (natural)

been downward according to residents contacted, levels appeared to vary. For 1990, Melfort reported no birds, Moose Jaw one and Prince Albert two. North Battleford noted seven birds downtown and Weyburn five of seven, both higher densities than in Saskatoon. There was too little data for an overall comparison of Regina and Saskatoon; as in Saskatoon, only one bird was observed in Regina's downtown area (Jon Triffio, pers. comm.).

Distribution Between 1971 and 1990, a major change occurred in the distribution of Saskatoon nighthawks. Numbers were down in all zones, except for the industrial one. The extreme was the downtown (commercial zone) area which harboured 16 males in 1971, but had just one in 1990. There was no obvious explanation. A few birds must travel farther for some of their feeding, face greater predation risks and find traditional gravelled roofing disappearing, yet these same factors applied in North Battleford and Weyburn where significant downtown occupancies still occurred.

Saskatoon's big, north industrial district was relatively unchanged at four home ranges compared to five previously and the airport industrial district had the only increase, to four from one. These two in combination with three other industrial tracts resulted in the city's industrial zoning having the second largest fraction of the nighthawk population.

$\begin{array}{rr}44 & 54 \\ 29 & 30 \\ 17 & 36 \\ 10 & 7\end{array}$

Redistribution in residential areas included abandonment of several isolated sites. This meant some suburbs had lost their neighbourhood nighthawks, thus creating the impression of a population even smaller than it proved to be. Male nighthawk occupancies by zones are shown in Table 1.

Twenty-two home ranges were in, overlapped, or near, open places, that is developed areas with large amounts of land not built upon, such as rights-of-way, landscaped expanses, industrial tracts, river banks and remnants of the Hudson Bay Sloughs. Use of these areas by nighthawks may have been for food or in some cases for nest sites (there are four records of nests on the ground in Saskatoon, 1964-1990).

The large expanse of gravelled roofing notwithstanding, no birds were reported at any of the major shopping centres. Despite the decline in numbers, 7 of the 28 ranges were on lands developed since 1971 and 14 were in the same locations as before - females often reuse previous years' nest sites. ${ }^{3}$

Behaviour Experience in 1971 had shown that there was considerable variation in the frequency and duration of peent-ing episodes. More than once, we discovered our neighbourhood bird would be silent while downtown birds were calling continuously for 15 to 30 minutes. From this and other instances, we 
suspected that the lower the density, the less the peent-ing. Our experience in 1990 certainly bore this out. With the frequency and duration of calls at lower levels and the calling period foreshortened, the effectiveness of using a survey method based on peent-ing characteristics was reduced. At times, despite repeat visits, failure to obtain completely satisfactory traces of the bird's path (because he did not peent often or long enough) was frustrating. A modified or alternative technique might have served better.

Unexpectedly, no nighthawks were reported between 12 July and the end of the survey on 25 July. Yet, in this latter part of the breeding season, 17 counts were conducted in 13 districts including seven in which birds had been heard on previous visits. In comparison, in 1971 , peent's were heard throughout July and 1 August's 21 observations of 15 birds was the season's high. For a few pairs to have abandoned their ranges early would not be unusual, but for most, if not all, to fall silent is perplexing. I suspect that this absence of peent's may have been due to the lower densities and nest predation. That is, a reaction similar to the current behaviour of local robins, which, now fewer and subjected to successive losses of nestlings to crows, sing less.

Only one other urban nighthawk survey repeated after a passage of years is known. A walking, circular $3.33 \mathrm{~km}$ transect of downtown Kitchener, Ontario, was performed in 1971 and repeated three times, the last being $1986 .^{10}$ The results indicated the population had remained stable. The procedure was similar to Saskatoon's, except for the number of counts and use of transects rather than area coverage. Striking was the great variation in numbers of birds seen per count in a given year, a low of three, a high of 12, suggesting similarity with the variable behaviour experienced in Saskatoon in 1990.

\section{Questions about the decline No} doubt, the mid-continent drop in numbers is a dominant factor in the decline of the Common Nighthawk in Saskatoon. ${ }^{1}$ During discussions about the study, however, possible contributory causes were suggested, including nest site preference, competition for food, the mosquito control program, physical status of roofing, predation and food resources.

Nesting on city roofs in the United States followed shortly after the introduction, 150 years ago, of tar and gravel roofing for flat roofs. ${ }^{2}$ However, whether this represented an overflow of birds from the countryside, or a preference for the artificial site is unknown. Recently in the Okanagan, Brigham found flat gravel roofs were not preferred roost or nest sites and he suggested a variety of factors may underlie the choice. ${ }^{4}$ Although data are meagre, the indication from the numbers of nighthawks using Field $A$ (natural nest sites), which in two decades decreased relatively more than elsewhere within the city (mostly artificial sites), was that roofs are preferred.

With both Big Brown and Little Brown Bats occurring in Saskatoon, survey observers were asked to note any sightings of them (Phil Taylor, pers. comm.). Four reported sites and two other known occupancies made six in all, though none contained significant numbers. Known colonies surrounding the city were all small. Marked competition for night-flying insects is unlikely.

Since 1984, the city has sprayed a larvicide specific to the mosquito on stagnant water bodies in a three-to- 
five- $\mathrm{km}$ belt surrounding the city. Spraying is from April through August to catch successive hatches, but is variable and depends on moisture conditions. It started on 11 July in 1990 (Tom McMurtry, pers. comm.). Of other cities contacted, only Prince Albert and North Battleford were without mosquito control measures. However, whether the current mosquito control program has any effect on urban-dwelling nighthawks is a matter for investigation. In the United States, the bird has been reported to consume quantities of mosquitoes as part of a diet that includes a wide variety of mainly night-flying insects. ${ }^{3}$ In the Okanagan Valley, recent studies showed that, although they were present, the smaller night-flying insects were not taken by nighthawks, the normal feeding mechanics of which, it is suggested, are unsuitable for taking smaller insects. ${ }^{5}$

Traditional asphalt and gravel roofing used pea gravel $(64$ to $127 \mathrm{~mm}$ in size) as ballast, or top dressing, and this presented a sufficient simulation for nighthawks. They laid their eggs directly on the flat ballast with no nest material or scrape. By the late 1970s, it was becoming common practice to apply a ballast of coarse gravel or crushed rock, 190 to 380 $\mathrm{mm}$ or more in size (Paul Juneau and Gordon Mickelson, pers. comm.). Most new flat roofing and much re-roofing (necessary every 20 to 35 years) is now constructed this way. Further, some downtown roofs now have non-ballasted smooth finishes, surfaces only occasionally used by nighthawks.

Although flat roofs are forecasted to remain common on large structures, the use of traditional roofing on them will decrease further. In newer industrial tracts, appearances deceive, for most flat-appearing roofs are not flat and the roofing is not gravel dressed. In general, in industrial tracts, gravelled roofs are to be found mainly on the older buildings. All this may adversely affect urban nighthawks. If the female nests on the coarser surface, her 30 $\mathrm{mm}$ egg may be inadequately covered by her brood patch or an egg may become lodged so she cannot rotate it for proper incubation.

Adoption of an urban elevated platform for a nest site in place of a rural patch of ground meant the bird traded one group of predators for another. Suggested as a possible predator was the crow, which was a resident of Saskatoon by 1971.6 All cities reported crows as common and only Weyburn noted that the ingress of crows may have peaked. After the initial brooding period, nestling nighthawks are at risk as they are fully exposed to daytime aerial predation. The crow's manner of hunting and its predation of nestling robins, make it suspect, although there are no known reports of nestling nighthawk predation by crows.

Merlins started increasing in Saskatoon in the early 1970s, their numbers now being steady, and several persons wondered whether they preyed on Common Nighthawks. The possibility is remote. A nighthawk kill has never been recorded in several thousand remains examined during Merlin studies in the city, and there is doubt a Merlin ordinarily could take an adult nighthawk (Lynn Oliphant, pers. comm.). Since the inception of the peregrine program in 1983 at a monitored site downtown, practically no nighthawk remains have been found in the kill residue, and nighthawks are considered only incidental prey for Peregrine Falcons (Pat Thompson, pers. comm.). 
Conclusions Repetition in 1990 of a 1971 survey showed changes in the population, distribution and behaviour of male Common Nighthawks in Saskatoon. The drop in numbers roughly mirrored changes in some other provincial centres. However, the urban population may have fared better than that in the natural areas of the surrounding region. Density decreased more than did the population and the lower density appeared to have influenced calling behaviour, which may have reduced the effectiveness of the count method. Whether behaviourial changes influenced reproduction rates is unknown. Over the past two decades insecticides, changes in flat roofing and possibly predation have likely reduced the urban population of nighthawks.

I am very grateful to the following for their key roles in conducting counts: John Eond, Ron Bremner, Paul Coutu, Hartley Fredeen, Mary Gilliland, Bernie Gollop, Ron Jensen, Harv Lane, Lynn Oliphant, Frank Roy, Stan Shadick, Gordon Silversides, Jim Slimmon, Al Smith, Phil Taylor, Guy Wapple, Michael Williams, Gary Wobeser and Lois Wooding. I thank others who contributed incidental records: Norma Allen, Gertrude Callin, Lloyd Saul, Alvena Schnell, Robert Wapple and Jim Wood. I appreciate the cooperation of those persons and their associates who provided information about their communities: Val Andrews, Moose Jaw; Louise Cochran, North Battleford; Genny Grief, Prince Albert; Frank Brazier, Jon Triffio and Frank Switzer, Regina; and Nick Postey, Weyburn. To Frieda Markland, Melfort, is due special thanks for going the extra mile - driving into town at 4:30 a.m. to search for nighthawks. I am indebted to a number of other persons who gave special advice, information or assistance: Glen Adams, Paul Juneau, Steve Marsden, Gord Mickelson, Tom McMurtry, Lynn Oliphant, Carol Ormiston, Ken Pivnick, Phil Taylor and Pat Thompson. I thank R. $M$. Brigham for his comments on a draft of this manuscript.

1. ARBIB, R.S. 1976. The Blue List for 1976. Am. Birds 29:1067-1072.

2. ARMSTRONG, J.T. 1965. Breeding home range in the Nighthawk and other birds; its evolutionary and ecological significance. Ecology 46: 619-629.

3. BENT, A.C. 1964. Life histories of North American cuckoos, goatsuckers, hummingbirds and their allies. Part I. Dover, New York. 244 pp.

4. BRIDGHAM, R.M. 1989. Roost and nest sites of Common Nighthawk. Condor 91:722-724.

5. — 1990. Prey selection of Big Brown Bats (Eptesicus fuscus) and Common Nighthawks (Chordeiles minor). Am. Midl. Nat. 124:73-80.

6. HOUSTON, C.S. 1977. Changing patterns of Corvidae on the prairies. Blue Jay 35:149-156.

7. KREBA, ROBERT. 1991.

Saskatchewan birds: American birds report - Fall 1990. Saskatchewan Natural History Society. Unpubl.

8. MARSDEN, S.P. 1988. Raptor rehabilitation at the Western College of Veterinary Medicine: a case review. Unpubl.

9. WEDGWOOD, J.A. 1973. Nighthawks in the city. Blue Jay 31:82-88.

10. WELLER, P. 1987. Monitoring an urban population of aerial foragers. Ontario Birds 5:69-71. 